\title{
As comunidades quilombolas brasileiras e a feminização da pobreza
}

\author{
Brazilian quilombola communities and the feminization of poverty
}

\author{
Sidimara Cristina Souza* \\ André Augusto Pereira Brandão** \\ Roberta Rezende Oliveira***
}

\section{Resumo}

Este artigo tem por objetivo refletir sobre as características socioeconômicas das comunidades negras rurais brasileiras, assim como sobre o processo de feminização da pobreza no interior desses territórios. Para tanto, utilizou-se como base de dados uma pesquisa realizada em 2011 pelo DataUFF, abrangendo 169 comunidades remanescentes de quilombo, localizadas em 14 estados brasileiros. Com a finalidade de desenvolver a proposta aqui empreendida, o artigo se estrutura da seguinte forma: A conceituação das comunidades remanescentes de quilombo; Reflexão teórica sobre a feminização da pobreza e a questão racial; Configuração socioeconômica das comunidades e os desdobramentos relacionados ao sexo. Por fim, faz-se uma discussão conclusiva sobre gênero e discriminação.

Palavras-chave: Pobreza. Feminização. Remanescente de quilombo.

\section{Abstract}

This article aims to reflect on the socioeconomic characteristics of Brazilian rural black communities, as well as the process of feminization of poverty within these territories. For this purpose, a research conducted in 2011 by the DataUFF, covering 169 remaining quilombo communities, located in 14 Brazilian states, is used as the database. With the purpose of developing the proposal undertaken here, the article is structured as follows: 1) The conceptualization of the remaining quilombo communities; 2) Theoretical reflection on the feminization of poverty and the racial question; 3) Socioeconomic configuration of communities and developments related to sex. Finally, there is a conclusive discussion on gender and discrimination.

Keywords: Poverty. Feminization. Remnant of quilombo.

\footnotetext{
* Graduada em Serviço Social. Doutoranda em Política Social pela Universidade Federal Fluminense (UFF). Email: <sidi.mara@hotmail.com>

** Graduado em Ciências Sociais. Doutor em Ciências Sociais. Professor associado da Universidade Federal Fluminense (UFF), atuando na graduação e no Programa de Pós-Graduação em Política Social. E-mail <andre_brandao@id.uff.br>.

${ }^{* * *}$ Graduada em Serviço Social. Doutora em Política Social e Assistente Social da Universidade Federal Fluminense (UFF). Email: robertaoliveira@id.uff.br.
} 


\section{Introdução}

Este artigo tem como objetivo realizar um exercício analítico acerca da caracterização das comunidades quilombolas no Brasil e o processo de feminização da pobreza nestes territórios.

Para a efetivação de tal proposta, trabalhou-se com dados oriundos de pesquisa previamente realizada em 2011 pelo DataUFF, com 169 comunidades, de 14 estados brasileiros (Pernambuco, Rio de Janeiro, São Paulo, Minas Gerais, Rio Grande do Sul, Goiás, Bahia, Sergipe, Amapá, Piauí, Maranhão, Mato Grosso do Sul, Mato Grosso e Pará), que tiveram o título de posse coletiva da terra emitido entre 1995 e 2011 pelo Instituto Nacional de Colonização e Reforma Agrária (INCRA), ou por órgãos oficiais estaduais de regularização fundiária.

Essa pesquisa empírica foi realizada tendo como foco o universo total de famílias residentes nas comunidades quilombolas pesquisadas. Em cada família foi aplicado um questionário visando a coleta de dados demográficos, socioeconômicos e relativos ao acesso aos programas sociais, com ênfase nas questões de renda e mercado de trabalho. No total foram aplicados 9.191 questionários. Foram coletados dados de todos os moradores residentes nos domicílios dos entrevistados, estando esses presentes ou não. Sendo assim, o banco de dados analisado é pautado na composição familiar, levando em consideração pessoas que tinham a residência pesquisada como domicílio habitual.

Para a produção deste trabalho também foi realizada pesquisa bibliográfica, referente à ordem racial socialmente construída no Brasil e seus reflexos no que tange à constituição socioeconômica, assim como a sua relação com a feminização da pobreza, dando ênfase à situação das mulheres das comunidades quilombolas. Para isso fez-se uso dos estudos publicados por: Costa et al. (2005), Melo e Castilho (2009), Rosa (2009), Novellino (2004), Melo e Sabbato (2013), Arruti (2008), Guimarães (2012), Brandão, Dalt e Gouveia (2010), entre outros autores.

Para orientar o estudo, partiu-se das seguintes inquietações: Qual a realidade que permeia as mulheres quilombolas na contemporaneidade? Quais as características da pobreza entre as mulheres quilombolas? Há diferenças socioeconômicas entre homens e mulheres nestas comunidades?

Com o intuito de alcançar o objetivo proposto e responder as questões elencadas, 0 trabalho apresentado seguirá a seguinte estrutura: 
1. Apresentação do debate em torno da conceituação de quilombo e remanescente de quilombo;

2. Discussão teórica sobre a feminização da pobreza e a relação com a questão racial;

3. Análise da configuração socioeconômica das comunidades remanescentes de quilombo estudadas com ênfase nas diferenças de gênero;

4. Conclusões acerca das marcas discriminatórias relacionadas ao sexo.

Seguindo a estrutura apresentada, busca-se alcançar o objetivo proposto, analisando o contexto socioeconômico das comunidades remanescentes de quilombo estudadas e a configuração encontrada relativa às relações entre homens e mulheres.

Entretanto, primeiramente se faz necessário um esclarecimento conceitual para que se possa diferenciar "gênero" e "sexo", pois de acordo com Rosa (2009), isso é necessário para que não haja uma leitura da tipologia "gênero" como uma categoria biológica. Sendo assim, trabalhou-se gênero como uma construção que permeia o contexto social, histórico e também cultural, sociologicamente construído, enquanto o sexo seria um termo usado para designar a diferença existente entre "machos" e "fêmeas" determinado pela biologia, ou seja, diferenças biológicas existentes entre homens e mulheres.

Mais especificamente, segundo Rosa (2009), trabalhar com o conceito de gênero é compreender as formulações político-científicas que atuam no intuito de "gerar a significação dessas diferenças como fenômenos sócio-histórico-culturais limitados no tempo e no espaço e passíveis de controle por parte dos indivíduos" (ROSA, 2009, p. 890). Ademais, a categoria gênero permite apreender a disputa de poder por trás das diferenças anatômicas entre os corpos, que são utilizadas a partir de uma construção simbólica que atua na ótica da naturalização, encobre as diferenciações de poder socialmente constituídas que visam preservar a estrutura social e manter as desigualdades das relações sociais.

Essa separação também deve ser feita no que tange às denominações cor e raça. Conforme destaca Guimarães (2003), a raça pode ter mais de um significado se observado do ângulo analítico: de um lado tem-se raça no sentido biológico, que determina a existência de apenas uma raça, a humana, mas também pode-se analisar o termo sociologicamente, uma vez que esta pode ser definida como dispositivo socialmente construído, ou seja, uma criação de cunho político, mas também científico atravessada por processos sócio-históricoculturais. Já a palavra cor, definida por Guimarães como uma categoria nativa, está 
relacionada às características físico-fenotípicas, relacionada à pigmentação da pele humana, servindo historicamente como elemento de discriminação e desigualdade.

\section{Quilombo e remanescente de quilombo: do conceito tradicional ao contemporâneo}

No contexto social, é muito recorrente a associação dos quilombos aos elementos relacionados ao período escravocrata e que teriam desaparecido do território brasileiro com a abolição da escravidão. Para Rattz (2006), no contexto colonial, os quilombos eram tomados como redutos de negros fugidos, e pejorativamente associados à rebeldia e à indisciplina.

Se, em tempos remotos, o conceito de quilombo esteve relacionado à luta pela liberdade, contemporaneamente, remete à luta pela terra. A busca pelo reconhecimento e pela redistribuição fundiária ganha força e visibilidade ao ser ancorada no Art. 68, componente do Ato das Disposições Constitucionais Transitórias (ADCT da Constituição Federal de 1988), que postula: “Aos remanescentes das comunidades de quilombos que estejam ocupando suas terras é reconhecida a propriedade definitiva, devendo o Estado emitir-lhes os títulos" (BRASIL, 1988).

Como se observa, a Constituição Federal de 1988 é um marco importante para as comunidades quilombolas, uma vez que dá visibilidade a um novo grupo social, via art. 68 do $A D C T$, conferindo-lhes direitos a propriedade da terra, além de criar uma nova nomenclatura, para as comunidades negras, a partir do termo remanescente ${ }^{1}$ de quilombo. Entretanto, o art. 68 do ADCT deixa em aberto o que caracterizaria essas comunidades, uma vez que não determina de forma precisa tal definição, fato esse que irá provocar diversos debates e conflitos judiciais.

Com o intuito de efetivar o Art.68 do ADCT, entra em vigor o Decreto 4.887, de 2003, que "regulamenta o procedimento para identificação, reconhecimento, delimitação, demarcação e titulação das terras ocupadas por remanescentes das comunidades quilombola" (BRASIL, 2003). Tal Decreto traz em seu Art.2o uma definição bastante específica para os remanescentes de quilombo:

\footnotetext{
${ }^{1}$ Vale destacar que não é referido ao remanescente no sentido de resto/sobra, mas conforme aponta Almeida (1998), como uma expressão do passado que se transmuta na relação de dependência estatal, sem perder, contudo uma certa autonomia, uma vez que "esquecidos" pelo Estado ainda preservam uma capacidade de sobrevivência, mobilização e organização.
} 
[...] os grupos étnico-raciais, segundo critérios de autoatribuição, com trajetória histórica própria, dotados de relações territoriais específicas, com presunção de ancestralidade negra relacionada com a resistência à opressão histórica sofrida (BRASIL, 2003).

A nova conceituação destaca que se constituir enquanto grupo étnico não exige necessariamente, que o território seja composto majoritariamente por negros e que esses estejam vinculados à uma trajetória histórica relacionada à escravidão. Embora possa haver uma "presunção de ancestralidade negra relacionada com a resistência à opressão histórica sofrida" (BRASIL, 2003), tal como consta do Decreto 4887/2003.

Conforme escreve Arruti (2008) o conceito de grupo étnico pressupõe uma definição de remanescentes de quilombos assentada em critérios subjetivos e contextuais pautados na contrastividade, que sugere a forma com um grupo se define e se percebe em oposição a um outro. Assim, o conceito de grupo étnico surge ancorado "à ideia de uma afirmação de identidade (quilombola) que é sintetizada pela noção de autoatribuição." (ARRUTI,2008, p. 23).

Para efeito desta pesquisa, toma-se como referência o conceito de remanescente de quilombo proposto pelo Decreto 4887/2003, o qual também se aproxima da definição de grupo étnico trazida por Arruti (2008), tal como discutida pela Associação Brasileira de Antropologia (ABA) e com ampla circulação no universo acadêmico: "[...] considera-se um grupo étnico a partir do momento em que, aceitando a distinção que lhe é imposta pela maioria, passa a utilizar-se politicamente dela na formação de agrupamentos autônomos ou com interesses e reivindicações comuns." (ARRUTI, 2008, p. 24).

De acordo com a Secretaria de Política de Promoção da Igualdade Racial - SEPPIR (BRASIL, 2012, p. 17), têm-se 1.948 comunidades reconhecidas oficialmente pelo Estado brasileiro; 1.834 certificadas pela Fundação Cultural Palmares (FCP); 1.167 com processos abertos para titulação de terras no Instituto Nacional de Colonização e Reforma Agrária (INCRA); 193 tituladas com área total de 988,6 mil hectares, beneficiando 11.991 famílias.

O processo de reconhecimento e de identificação enquanto remanescente de quilombo é marcado por conflitos identitários e étnicos, fazendo com que haja morosidade no que tange ao longo caminho que vai do autorreconhecimento até a legalização da declaração enquanto tal.

Conforme descrito por Jorge (2014), desde a Constituição federal de 1988 até o primeiro acesso de uma comunidade quilombola ao título definitivo de suas terras, 
passaram-se 7 anos. De fato, as comunidades quilombolas só começam a acessar o direito da posse definitiva da terra quando passam a se reconhecer como tais. Assim, somente em 1995 a primeira comunidade remanescente de quilombo obteve a titulação. Isso ocorreu no estado do Pará, no município de Oriximiná.

Após o reconhecimento enquanto comunidade quilombola, uma série de ações burocráticas precisam ser realizadas pelo grupo para que possa então pleitear a propriedade coletiva definitiva de seus territórios. Com o intuito de nortear tal fluxo administrativo, entra em vigor em 2009 a Instrução Normativa-IN no 57. Este é um marco legal que busca regulamentar o Decreto no 4.887/2003, e "estabelece procedimentos do processo administrativo para identificação, reconhecimento, delimitação, demarcação, desintrusão, titulação e registro das terras ocupadas pelos remanescentes de comunidades dos quilombos." (INCRA, 2009).

Carece ser destacado que antes de solicitar a titulação das terras ao INCRA, as comunidades quilombolas precisam ter a Certidão de Registro no Cadastro Geral de Remanescentes de Comunidades de Quilombos emitida pela Fundação Cultural Palmares. Conforme a Portaria FCP no 98/2007 para obter a emissão da Certidão as comunidades precisam seguir alguns requisitos. Primeiramente, caso a comunidade não tenha uma associação constituída e com o seu Cadastro Nacional da Pessoa Jurídica (CNPJ) regularizado deverá apresentar: ata de reunião convocada da assembleia, constando que a finalidade dessa é de deliberação a respeito da autodefinição da comunidade enquanto remanescente de quilombo. Tal ata deve ser aprovada pela maioria dos moradores e acompanhada da lista de presença devidamente assinada. Entretanto, se a comunidade já tem uma associação legalmente constituída cadastrada, a ata só será assinada pelos membros da associação.

O grupo que solicita a Certidão, ou seja, o registro enquanto comunidade quilombola deve encaminhar à FCP, caso a comunidade os possua, dados, documentos ou informações, tais como fotos, reportagens, estudos realizados, entre outros, que atestem a história comum do grupo ou suas manifestações culturais. O grupo também deve apresentar um relato narrando a história da comunidade. Junto aos documentos elencados, a associação, ou os moradores, devem redigir um ofício e solicitar ao Presidente da FCP a emissão da certidão de autodefinição.

Só depois de ter conseguido a certificação enquanto remanescente de quilombo, as comunidades podem solicitar a titulação de suas terras. Para isso, precisam manifestar 
interesse via documento redigido por algum representante local, ou pelo INCRA, conforme descrito no Art. 70 da Instrução Normativa no 57/2009, para em seguida dar andamento aos estudos técnicos e científicos, contribuindo para a elaboração de relatórios antropológicos, denominados de Relatório Técnico de Identificação e Delimitação - RTID, que tem como objetivo descrever as características do território e apresentar os fatores econômicos, ambientais e socioculturais.

A produção deste relatório fica a cargo da Superintendência Regional do INCRA e deve ser aprovada pelo Comitê Regional do INCRA e após aprovação, encaminhada para órgãos como: IBAMA, FUNAI, Instituto Chico Mendes dentre outros, com o intuito de buscar a ciência destes, uma vez que o território diagnosticado como pertencente a uma comunidade quilombola pode estar situado dentro das margens de competência de algum destes órgãos. Em seguida, o relatório é publicado e o INCRA passa a analisar a situação fundiária da área pleiteada. Só depois de todo este processo a terra será demarcada e titulada coletivamente, de acordo com a Instrução Normativa no 57/2009. Todos esses requisitos constituem o caminho percorrido até a titulação da terra.

Como pode ser observado, o reconhecimento enquanto comunidade remanescente de quilombo é lento e burocrático, além de envolver a construção de um processo identitário étnico, pois é a partir do autorreconhecimento como quilombo que se torna possível pleitear junto à Fundação Cultural Palmares a certificação de existência como tal.

Após esta discussão introdutória acerca da categoria "remanescente de quilombo", buscou-se refletir sobre o que representaria o conceito de feminização da pobreza. Será necessário também entender qual a relação desse fenômeno com a categoria raça (em seu sentido social). Somente a partir daí conseguiu-se realizar a análise sobre a realidade que permeia determinadas comunidades negras rurais e as desigualdades locais no que tange à desigualdade de gênero.

\section{A feminização da pobreza e sua relação com a questão racial: reflexões acerca da temática}

De acordo com Novellino (2004) a expressão "feminização da pobreza" foi criada por Diane Perce em 1978, em um trabalho publicado na Urban and Social Change Review. Nesta acepção, a feminização da pobreza seria um fenômeno diretamente relacionado à configuração da família, que por diversos motivos, passa a ser composta pela mulher e seus 
filhos, resultando em uma configuração na qual a mulher se torna a responsável principal pelas despesas do domicílio.

Costa et al. (2005) relata que não há um conceito único para a expressão "feminização da pobreza", e que muitos estudos vêm discutindo a temática, permeando reflexões sobre gênero e pobreza, além de considerar a composição e distribuição intradomiciliar. Ainda segundo a autora, estudos vinculados ao que a Organização Internacional do Trabalho (OIT) chama de determinantes de gênero, apontam para alguns fatores que incidem no nível de vulnerabilidade das pessoas interferindo na propensão das mesmas à pobreza, bem como nas possibilidades de superá-la. Como exemplos destes determinantes de gênero elencam-se aspectos, tais como: desigualdade na participação no mercado de trabalho; desvalorização social e econômica das tarefas predominantemente femininas; desigualdade no acesso aos recursos produtivos e, desigualdade de oportunidade na participação dos espaços de tomadas de decisão.

Conforme destaca Costa et al. (2005), a ideia de que a maioria dos indivíduos situados na extrema-pobreza ou na pobreza são do sexo feminino é defendida e discutida por significantes instituições internacionais, como é o caso do Programa das Nações Unidades para o Desenvolvimento (PNUD), que em 1995, via Relatório de Desenvolvimento Humano, apontava que $70 \%$ da população pobre do mundo eram mulheres.

Outro marco internacional de grande relevância que se refere à feminização da pobreza é a IV Conferência Mundial sobre a Mulher que ocorreu em Beijing/China, em 1995. Tal evento reafirma que o número de mulheres pobres é muito maior do que de homens pobres, principalmente nos países desenvolvidos que se estruturam em ideias neoliberais cada vez mais enraizadas.

Foi observado que, desde o final da década de 1970, diversas definições permearam o fenômeno denominado de feminização da pobreza. Entretanto, ainda não foi alcançado um consenso. Para o desenvolvimento desse trabalho, levou-se em consideração o déficit socialmente produzido em torno das mulheres em relação aos homens, observando as desigualdades no que tange ao mercado de trabalho, bem como na composição familiar. Além disso, foi dado ênfase ao agravamento da pobreza entre as mulheres correlacionado às variáveis como escolaridade, renda, chefia do domicílio, entre outros elementos.

Compartiu-se com o conceito de feminização da pobreza trabalhado por Medeiros e Costa (2008, p. 1), apresentado na 58o edição da circular do Centro Internacional da 
Pobreza. Tal conceito tem recebido grande aceitação por muitos estudos relacionados à temática. Para os autores, a feminização da pobreza refere-se à mudança nos níveis de pobreza que parte do viés desfavorável das mulheres em relação aos homens; bem como dos domicílios chefiados pelas figuras femininas quando comparados aos domicílios chefiados pela figura masculina, ou até mesmo por casais. Assim, o termo pode significar ainda o aumento da pobreza entre as mulheres devido às desigualdades de gênero, o que é interpretado pelos autores como feminização das causas da pobreza.

Toma-se a pobreza como fenômeno multidimensional, fundado em um conjunto de fatores provenientes do não acesso à saúde, educação, ao lazer, habitação, ao trabalho, infraestrutura social, alimentação - entre outros elementos que fazem parte dos direitos garantidos pela Constituição Federal de 1988, mas que ainda não são acessíveis a todos (SILVA, 2010). Sendo assim, contempla-se a pobreza, considerando "o acesso aos bens, recursos e serviços sociais, ao lado de outros meios complementares de sobrevivência" (YAZBEK, 2012, p. 292). No que diz respeito à feminização, considerou--se os acontecimentos relacionados à pauperização que tendem a se tornar mais expressivos entre as mulheres se comparado aos homens (MEDEIROS; COSTA, 2008).

Porém o cenário da pobreza brasileira, além de ter sexo, também tem cor. Conforme mostra Rosa (2009, p. 892-3), as desigualdades sociais entre mulheres negras são ainda maiores, pois essas são mais pobres, quando comparadas à mesma proporção entre mulheres e homens brancos, sendo que a renda média da principal ocupação de uma mulher negra em 2007 era de aproximadamente 2,92 vezes abaixo da renda principal dos homens brancos. Vale destacar que foi considerado mulheres negras como grupo de pessoas que se autodeclaram pretas e pardas, conforme classificação do Instituto Brasileiro de Geografia e Estatística - IBGE.

Segundo Rosa (2009), no ano de 2007, a Pesquisa Nacional por Amostra de Domicílios-PNAD, realizada pelo Instituto Brasileiro de Geografia e Estatística-IBGE mostra que $30,8 \%$ do universo total de brasileiros poderiam ser caracterizados como pobres, sendo que desses, $19,7 \%$ se enquadravam no grupo dos brancos e $41,7 \%$ no grupo dos pretos.

Relatório Anual Socioeconômico da Mulher - RASEAN, publicado em 2014, traz dados importantes que podem ajudar a pensar o fenômeno da feminização brasileira, no que tange à mudança na organização familiar. De acordo com o relatório, está havendo crescimento no número de arranjos familiares compostos por mulheres com filhas(os) e sem 
marido. Os dados apontam que entre as famílias chefiadas por mulheres, $42,7 \%$ são compostas por mulheres com filhas(os) e sem marido.

Outro dado importante, diagnosticado pelo RASEAM (BRASIL, 2014), aponta que em 2012 tinha mais de 51\% da população brasileira do sexo feminino, e desse universo se declaravam como pretas ou pardas $51,7 \%$ das mulheres.

Esses dados mostram que são múltiplas e heterogêneas as expressões da discriminação e que as mesmas estão se atualizando constantemente, de acordo com a dinâmica da sociedade e sua relação com a ordem racial e de gênero que vem sendo socialmente construída ao longo da história (ROSA, 2009).

Um fator relevante que aparece nos dados do RASEAM (BRASIL, 2014) é relacionado ao crescimento de famílias unipessoais. O relatório apresenta que $17,5 \%$ das famílias que têm mulheres como referência são constituídas por apenas uma pessoa.

Os breves dados apresentados reafirmam que os reflexos da pauperização brasileira serão muito mais perversos no universo feminino. Isto fica mais claro ainda, quando são analisadas as relações entre as mulheres e o mundo do trabalho, fato que comprova que há uma "designação prioritária dos homens à esfera produtiva e para as mulheres a esfera reprodutiva e, simultaneamente, a apropriação pelos homens de funções com maior valor social" (CARLOTO; GOMES, 2011, p. 133), reproduzindo as facetas da discriminação.

Os dados sobre pobreza no Brasil também demonstram que os processos de exclusão do acesso à renda acabam tendo incidência na produção de pobreza em grupos específicos. Os dados da PNAD indicam que, em 2007, 30,8\% de todos os brasileiros poderiam ser considerados pobres, no entanto, a proporção de pobres entre os brancos era de 19,7\%, enquanto entre negros era de 41,7\% (ROSA, 2009, p. 894).

Em resumo pode-se dizer que diversos fatores, construídos historicamente, são responsáveis pela manifestação dos reflexos da desigualdade social no que tange às variáveis raça e sexo, reforçando ações discriminatórias. Com o intuito de conhecer as iniquidades relacionadas a esse processo sexista e racista é que buscou-se no próximo tópico apresentar dados encontrados a partir de pesquisa realizada junto à comunidades quilombolas. 


\section{Configuração socioeconômica das comunidades remanescentes de quilombo: as desigualdades relacionadas ao sexo}

Conforme estudos realizados pelo CEDEFES (2008) e Brandão, Dal e Gouveia (2010), as comunidades remanescentes de quilombo sofrem diversas mazelas como falta de saneamento básico, energia elétrica, água tratada, posto de saúde, pavimentação e melhoramento das estradas de acesso, educação contextualizada, entre outras tantas carências, fazendo com que estejam enquadradas em uma situação de extrema vulnerabilidade. Neste tópico adentrou-se à caracterização socioeconômica das comunidades, dando ênfase às desigualdades relacionadas ao sexo.

A partir da pesquisa realizada pelo DataUfF (2011), junto a 169 comunidades quilombolas que já possuem o título de posse da terra, pode-se traçar uma breve caracterização das comunidades estudadas para em seguida fixar-se nas desigualdades relacionadas ao sexo no interior desses territórios.

No que diz respeito à variável sexo, $52 \%$ dos moradores das comunidades pesquisadas se declararam do sexo feminino, conforme pode ser observado no gráfico 01 . Estes dados mostram que a população feminina é superior à masculina nestes espaços, na mesma direção da média brasileira que é composta por 51,7 \% de mulheres, segundo o IBGE (Instituto Nacional de Geografia e Estatística, 2018) por meio da PNAD (Pesquisa Nacional por Amostra de Domicílios).

Gráfico 1: Sexo dos moradores

\section{SEXO DOS MORADORES}

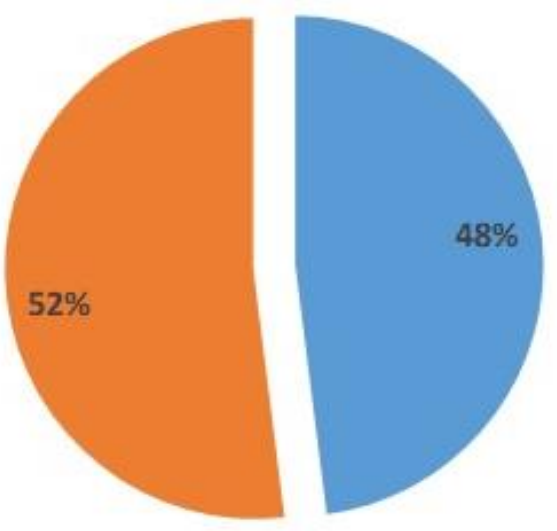

- HOMENS

- MULHERES

Fonte: Elaboração a partir dos dados da pesquisa do IBGE (2018) 
No que tange à faixa etária dos moradores, a maioria se encontra entre 20 e 39 anos, totalizando $26,98 \%$ dos núcleos familiares, ou seja, tem-se uma população composta por jovens, sendo que o grupo de 0 a 6 anos de idade é mais do que a metade da população de idosos $(7,87 \%)$, correspondendo a $17,2 \%$. Este é um fator que diverge dos dados encontrados pelo IBGE (2014) para o conjunto da população brasileira. Isso porque, segundo dados do IBGE (2014), há uma tendência de envelhecimento da estrutura etária do país, incorrendo no estreitamento da base da pirâmide populacional que é composta por grupos mais jovens.

Na distribuição etária da população de 2013, observou-se que este estreitamento da base da pirâmide foi ainda mais destacado. No período analisado, verificou-se que a participação do grupo com até 29 anos de idade diminuiu de 54,4\%, em 2004, para 46,6\% em 2013, enquanto o aumento para o grupo com 45 anos ou mais de idade foi evidente, passando de $24,0 \%$ para $30,7 \%$, no mesmo período (IBGE, 2014).

Em relação à variável raça, utilizando a classificação do IBGE (branco, pardo, preto, amarelo e indígena), mais de $50 \%$ do universo total pesquisado (mulheres mais homens) se declara como preto. No que concerne às mulheres, $25,46 \%$ se declaram como pretas. Conforme analisado o número de pessoas que se declara preto ou pardo, pode-se dizer que mais de $90 \%$ da população pesquisada é autodeclarada negra. No que diz respeito à média nacional, 53,92\% da população em 2015 se autodeclaravam preta ou parda, segundo dados da PNAD.

Ainda caracterizando os territórios quilombolas estudados, foi destacado que mais da metade da população possui no máximo até o ensino fundamental, sendo que $18,4 \%$ nunca estudaram. Se somar o número de entrevistados do sexo feminino que estudou e atingiu mais de 9 anos de estudos, tem-se um montante de 6,83\%, valor que é ainda menor no grupo masculino que chega a pouco mais do que $5 \%$ do total.

Em relação à condição dos moradores das casas e o sexo, constata-se que 17,56\% das mulheres são consideradas como a pessoa de referência do domicílio. Número este inferior à média nacional, pois segundo o IBGE (2010), 37,3\% das casas brasileiras tinham a mulher como responsável. Entretanto, ao separar os domicílios rurais e urbanos do país, apenas $24,8 \%$ das residências rurais são chefiadas por mulheres, dado que pode explicar o porquê de nas comunidades quilombolas pesquisadas (que são quase predominantemente rurais) a porcentagem de domicílios com mulheres como pessoa de referência seja menor. 
Em relação ao número de moradores por residência, observa-se que a maior frequência está nas famílias compostas por até 5 pessoas, conforme demostrado no quadro 01. Se for observado por sexo, pode-se perceber que a maioria das mulheres reside em casas de 2 a 5 pessoas.

Quadro 1: Quantitativo de pessoas por domicílio

\begin{tabular}{|l|l|l|l|l|}
\hline \multirow{2}{*}{ Pessoas por domicílio } & Feminino & \multicolumn{2}{l|}{ Masculino } \\
\cline { 2 - 5 } & No & \% & No & \% \\
\hline 15 ou mais moradores & 77 & 0,39 & 90 & 0,43 \\
\hline 10 a 14 moradores & 1455 & 7,42 & 1504 & 7,18 \\
\hline 6 a 9 moradores & 7364 & 37,55 & 7893 & 37,70 \\
\hline 2 a 5 moradores & 10461 & 53,34 & 11016 & 52,61 \\
\hline 1 morador & 254 & 1,30 & 434 & 2,07 \\
\hline Total & 19611 & 100,00 & 20937 & 100,00 \\
\hline
\end{tabular}

Fonte: Elaboração a partir dos dados da pesquisa do DataUFF (2011)

Com o intuito de analisar as desigualdades existentes entre homens e mulheres, destacando a variável sexo, a tabela 01 fornece dados sobre os meios de recebimento de dinheiro dos domicílios. Foi observado a vulnerabilidade das mulheres em relação aos homens no que tange à aquisição de renda por meio de alguma atividade. A proporção é quase igual no que tange ao trabalho remunerado o ano todo (formato pouco acessado pela população quilombola). Excetuando o artesanato, ou a produção cultural (com resultado ínfimo), nas demais formas de obtenção de renda por domicílio, há predomínio masculino. Nas aposentadorias, no entanto, as mulheres predominam. O não recebimento de renda é mais frequente entre mulheres quando comparado aos homens, fator que pode ser explicado pela sua longa jornada de trabalho doméstico não remunerado.

Tabela 1: Frequência de meios de recebimento de dinheiro $X$ sexo

\begin{tabular}{|c|c|c|c|c|}
\hline \multirow{3}{*}{ Nos últimos 12 meses, recebeu algum dinheiro por meio de: } & \multicolumn{4}{|c|}{ Sexo } \\
\hline & \multicolumn{2}{|c|}{ Feminino } & \multicolumn{2}{|c|}{ Masculino } \\
\hline & no & $\%$ & no & $\%$ \\
\hline Venda do cultivo ou criação de animais & 1044 & 5,3 & 2029 & 9,7 \\
\hline Trabalho remunerado - ano todo & 884 & 4,5 & 983 & 4,7 \\
\hline Trabalho remunerado - temporário & 241 & 1,2 & 547 & 2,6 \\
\hline Trabalho remunerado - diarista & 433 & 2,2 & 1955 & 9,3 \\
\hline Venda de artesanato ou produção cultural & 101 & 0,5 & 77 & 0,4 \\
\hline
\end{tabular}




\begin{tabular}{lllll}
\hline Aposentadoria & 1608 & 8,2 & 1221 & 5,8 \\
Nenhum & 13559 & 69,2 & 12426 & 59,4 \\
NS/NR/NA & 1740 & 8,9 & 1700 & 8,1 \\
\hline Total & 19610 & 100,0 & 20938 & 100,00 \\
\hline
\end{tabular}

Fonte: Elaboração própria a partir dos dados da pesquisa do DataUFF (2011)

Conforme verificado a partir dos dados apresentados, a frequência dos meios de recebimento de recurso entre homens e mulheres é bem diferente. Aspecto este que se relaciona ao acesso à renda, pois se não há meios de geração de recurso, automaticamente não há poder aquisitivo proporcionalmente positivo. A disparidade representada acima pode ser explicada, pela relação estabelecida pela divisão sexual do trabalho. Isso porque, as condições de vida de homens e mulheres são produtos de construções sociais tendo o trabalho como base material. Assim, enquanto a maioria dos homens é lançada às atividades no mercado de trabalho capitalista (trabalho produtivo); as mulheres são "naturalmente" obrigadas a dividir seu tempo entre a produção de mercadorias fora de casa e a realização das tarefas domésticas e de cuidados (trabalho reprodutivo), ou seja, acabam sendo levadas a conciliar trabalho remunerado e trabalho não remunerado (MELO; CASTILHO, 2009, p. 137).

Também atentou-se para as informações obtidas sobre aposentadoria, uma vez que o número de mulheres aposentadas é $2,4 \%$ maior se comparado com o total masculino, fator que pode ser explicado pela maior expectativa de vida das mulheres, conforme apontamento do DATANASPS (ANASSP, 2013).

Porém é importante ressaltar que:

As mulheres são quem menos usufruem os resultados práticos e monetários oriundos do seu trabalho no mundo das mercadorias e na reprodução da vida. $A$ segmentação do mercado de trabalho reflete-se no fato de a maioria das aposentadorias das mulheres se concentrarem em benefícios de baixo valor, e em média 39\% inferiores ao valor das masculinas (MELO; OLIVEIRA, 2009, p. 107).

Assim, o fato das mulheres representarem numericamente uma porcentagem mais significativa de beneficiárias da Previdência Social não quer dizer que elas sejam as grandes responsáveis pelos gastos previdenciários, tampouco que seus rendimentos podem ser equiparados aos ganhos masculinos ${ }^{2}$. Também não se pode deixar de destacar que, mesmo que essas mulheres estejam cobertas pelo regime especial da previdência social, as mesmas

\footnotetext{
${ }^{2}$ Para um estudo mais aprofundado sobre a Previdência Social e o mundo feminista, ler: Melo e Oliveira (2009).
} 
possuem grandes dificuldades de acesso ao benefício previdenciário da aposentadoria, uma vez que "os critérios androcêntricos de comprovação do trabalho rural dificultam a incorporação das mulheres", conforme mostra o trabalho de Brandão e Jorge (2012, p. 172).

No que diz respeito à frequência de meios de recebimento de dinheiro em relação a cor, foi observado na tabela 02 que o número de pessoas por domicílio, de cor preta e parda, que não possuem nenhuma fonte de renda é superior a $59 \%$ dos pesquisados. Dados que reforçam a desigualdade de raça, mostrando que as pessoas brancas tendem a ter mais mecanismos de geração de renda do que os negros.

Tabela 2: Frequência de meios de recebimento de dinheiro x Cor.

\begin{tabular}{lrrrrr}
\hline \multicolumn{1}{c}{ Meios de recebimento de dinheiro } & Branca & Preta & Parda & Outras & Total \\
\hline & & & & \\
Venda do cultivo ou criação de animais & 111 & 1743 & 1126 & 93 & 3073 \\
& $7,6 \%$ & $8,1 \%$ & $7,0 \%$ & $5,8 \%$ & $7,6 \%$ \\
Trabalho remunerado - ano todo & 95 & 1084 & 610 & 78 & 1867 \\
& $6,5 \%$ & $5,0 \%$ & $3,8 \%$ & $4,8 \%$ & $4,6 \%$ \\
Trabalho remunerado - temporário & 32 & 486 & 239 & 31 & 788 \\
& $2,2 \%$ & $2,3 \%$ & $1,5 \%$ & $1,9 \%$ & $1,9 \%$ \\
Trabalho remunerado - diarista & 99 & 1166 & 1008 & 115 & 2388 \\
& $6,8 \%$ & $5,4 \%$ & $6,3 \%$ & $7,1 \%$ & $5,9 \%$ \\
Venda de artesanato ou produção cultural & 5 & 101 & 57 & 15 & 178 \\
& $0,3 \%$ & $0,5 \%$ & $0,4 \%$ & $0,9 \%$ & $0,4 \%$ \\
Aposentadoria & 130 & 1629 & 941 & 129 & 2829 \\
& $8,9 \%$ & $7,6 \%$ & $5,9 \%$ & $8,0 \%$ & $7,0 \%$ \\
Nenhum & 872 & 13290 & 10837 & 986 & 25985 \\
& $59,5 \%$ & $61,9 \%$ & $67,8 \%$ & $61,1 \%$ & $64,1 \%$ \\
NS/NR & 122 & 1975 & 1165 & 166 & 3428 \\
NA & $8,3 \%$ & $9,2 \%$ & $7,3 \%$ & $10,3 \%$ & $8,5 \%$ \\
\hline Total & 0 & 9 & 1 & 2 & 12 \\
\hline
\end{tabular}

Fonte: Elaboração própria a partir dos dados da pesquisa do DataUFF (2011).

Quando relaciona-se a frequência dos moradores que estão trabalhando com a variável sexo, é possível dizer que assim como grande parte das mulheres não possui nenhuma renda, 66,8\% das mulheres dos domicílios também não estão trabalhando, percentual que fica quase 8 pontos acima do apresentado pelos homens, de acordo com a tabela 03. Além disto, de acordo com o banco de dados fornecido pelo DataUFF (2011), do total de $23,5 \%$ de mulheres que estão trabalhando, apenas $7,7 \%$ realizam atividades laborais com carteira assinada. 
Tabela 3: Frequência de trabalho X Sexo

\begin{tabular}{|c|c|c|c|c|}
\hline \multirow{3}{*}{ Está trabalhando } & \multicolumn{4}{|c|}{ Sexo } \\
\hline & \multicolumn{2}{|c|}{ Feminino } & \multicolumn{2}{|c|}{ Masculino } \\
\hline & $\mathrm{n}$ & $\%$ & $\mathrm{n}$ & $\%$ \\
\hline Sim & 4609 & 23,5 & 7162 & 34,2 \\
\hline Não & 13103 & 66,8 & 12159 & 58,1 \\
\hline Não, é aposentado. & 1293 & 6,6 & 983 & 4,7 \\
\hline NS/NR & 600 & 3,1 & 629 & 3,0 \\
\hline Total & 19605 & 100,0 & 20933 & 100,0 \\
\hline
\end{tabular}

Fonte: Elaboração própria a partir dos dados da pesquisa do DataUFF (2011)

Os dados apresentados são uma amostra da situação em que se encontram as comunidades remanescentes de quilombo do Brasil. Conforme o relatório apresentado pela SEPPIR (BRASIL, 2012), 75,6\% dos territórios quilombolas titulados se encontram na extrema pobreza. Nestes territórios $62 \%$ dos domicílios não possuem água tratada e canalizada; $76 \%$ não têm acesso ao saneamento básico; $58 \%$ não possuem coleta do lixo e $36 \%$ não contam com banheiro ou sanitário (mesmo existindo programas e projetos que têm como foco atender as essas necessidades básicas no interior dos territórios quilombolas). Além disto, 23,5\% da população dos territórios quilombolas não sabe ler nem escrever. Esses dados alertam quanto a situação de vulnerabilidade social em que se encontram as comunidades quilombolas, o que gera impactos significativos sobre as mulheres.

\section{Conclusões}

Conforme elucidado no decorrer do trabalho apresentado, destacou-se que os reflexos da pauperização e da discriminação relacionados a raça e sexo são expressivos. Primeiro ressaltar que o próprio objeto de estudo já se encontra em uma situação de vulnerabilidade social de destaque, segundo dados apresentados por Brandão, Dalt e Gouveia (2010), Cedefes (2008) e SEPPIR (BRASIL, 2012). Outro elemento importante a ser apontado a partir dos dados analisados é que as mulheres estão em menor quantidade que os homens em atividades que geram renda. Assim, como na sociedade brasileira no geral, as comunidades quilombolas reproduzem o processo de discriminação relacionado ao sexo, que se agrava ainda mais por serem comunidades rurais e negras.

A mulher encontra-se localizada em uma estrutura extremamente patriarcal, principalmente nos territórios rurais, como é o caso das comunidades estudadas, marcada 
por subordinação, sendo a ela atribuídos os trabalhos domésticos e a figura reprodutora. Estes são elementos que contribuem para reforçar a submissão da mulher, desvalorizando o labor feminino, pois esse é lido socialmente como uma ação complementar com a do homem.

Pode-se afirmar que a mulher arca com uma sobrecarga de trabalho muito maior do que a do homem. Esta porém, não é reconhecida e remunerada, pois as atividades que desenvolve são tomadas como um trabalho reprodutivo e não produtivo, como viu--se anteriormente, o que contribui para que o sexo feminino esteja alocado em grupos com grande expressividade nas mazelas sociais.

De modo geral, foi concluído que os territórios dos remanescentes de quilombo pesquisados são marcados por diversos processos discriminatórios como, por exemplo, o sexo. Porém, por serem comunidades compostas em maioria por pretos e pardos, a variável cor não traz elementos significativos ao ser feito o cotejamento entre pretos e brancos, mas afirma que o processo de pauperização dos remanescentes de quilombo tende a ter o retrato feminino.

Por fim, foi ressaltado que as mulheres, via movimento feminista, vêm ganhando reconhecimento e se posicionando de forma enfática na vida social e política, conquistando muitas vitórias como: a regularização do trabalho doméstico (Lei 224/13), a ampliação de políticas públicas, e a criação de leis que as proteja da violência masculina, como é o caso da Lei $n$ o 11.340, de 7 de agosto de 2006, mais conhecida como Lei Maria da Penha. Todavia, ainda continuam em patamar de desigualdade em relação à valorização dos homens perante a sociedade.

\section{Referências}

ALMEIDA, A. W. B. Quilombos: repertório bibliográfico de uma questão redefinida (19951997). In: BIB. Rio de Janeiro, no 45, 10 semestre de 1998 pp. 51-70.

ARRUTI, José Maurício. Quilombos. In: PINHO, Osmundo; SANSONE, Livio. Raça: perspectivas antropológicas (org.). Salvador: EDUFBA, 2008.

ANASSP - ASSOCIAÇÂO NACIONAL DOS SERVIDORES DA PREVIDÊNCIA E DA SEGURIDADE SOCIAL. DATANASPS revela que cresce o número de aposentadorias e pensionistas com mais de 90 anos. 2013. Disponível em: http://www.anasps.org.br/mostra materia. php?id=3587. Acesso em: 31 jul. 2015. 
BRANDÃO, André Augusto Pereira; JORGE, Amanda Lacerda. Androcentrismo institucional e acesso a aposentadoria rural entre mulheres quilombolas da comunidade de Agreste-MG. Revista Ártemis, João Pessoa, v. 13, p. 161-173, jan./jun., 2012.

BRANDÃO, André; DALT, Salete; GOUVEIA, Victor Hugo. Comunidades quilombolas no Brasil: características socioeconômicas, processos de etnogênese e políticas sociais. Rio de Janeiro: Eduff, 2010.

BRASIL. [Constituição (1988)]. Constituição da República Federativa do Brasil de 1988. Brasília, DF: Presidência da República, 1988. Disponível em:

http://www.planalto.gov.br/ccivil_03/constituicao/constituicao.htm. Acesso: em 8 jul. 2015.

BRASIL. Decreto $n=4887$ de 20 de novembro de 2003. Regulamenta o procedimento para identificação, reconhecimento, delimitação, demarcação e titulação das terras ocupadas por remanescentes das comunidades dos quilombos de que trata o art. 68 do Ato das Disposições Constitucionais Transitórias. Brasília, DF: Casa Civil, 2003. Disponível em: http://www.planalto.gov.br/ccivil_03/decreto /2003/D4887.htm. Acesso em: 10 jul. 2015.

BRASIL. Relatório anual socioeconômico da mulher-RASEAM. Brasília: Secretaria de Políticas para as Mulheres, 2014.

BRASIL. Secretaria Especial de Políticas de Promoção da Igualdade Racial. Programa Brasil quilomba: comunidades quilombolas brasileiras regularização fundiária e políticas públicas. Brasília: SEPPIR, 2012. Disponível em: www.seppir.gov.br. Acesso em: 12 jul. 2015.

CARLOTO, Cássia Maria; GOMES, Anne Grace. Geração de renda: enfoque nas mulheres pobres e divisão sexual do trabalho. Serviço Social e Sociedade, São Paulo, n. 105, jan./mar. 2011. Disponível em: http://www.scielo.br/pdf/sssoc/n105/08.pdf. Acesso em: 11 jul. 2015.

CEDEFES - CENTRO DE DOCUMENTAÇÃO ELOY FERREIRA DA SILVA. Comunidades quilombolas de Minas Gerais no século XXI: história e resistência. Belo Horizonte: Autêntica: CEDEFES, 2008.

COSTA, Joana Simões; PINHEIRO, Luana; MEDEIROS, Marcelo; QUEIROZ, Cristina. A face feminina da pobreza: sobre-representação e feminização da pobreza no Brasil. Brasília: IPEA, 2005. Disponível em: http://www.ipea.gov.br/portal/images/stories /PDFs/TDs/td_1137.pdf. Acesso em: 8 jul. 2015.

DATAUFF. Avaliação da situação de segurança alimentar e nutricional em comunidades quilombolas tituladas. Niterói, RJ: DataUFF: Núcleo de Pesquisa da Universidade Federal Fluminense, 2011. [Relatório de Pesquisa].

GUIMARÃES, Antonio S. "Democracia racial". IN: Guimarães, Antonio S. Classes, Raças e Democracia no Brasil. São Paulo: Ed.36, 2012.

GUIMARÃES, Antonio Sérgio. Como trabalhar com "raça" em sociologia. Educação e Pesquisa, São Paulo, v. 29, n. 1, p. 93-107, 2003. Disponível em:

http://www.scielo.br/pdf/ep/v29n1/a08v29n1.pdf. Acesso em: 10 jul. 2015. 
IBGE - Instituto Brasileiro de Geografia e Estatística. Censo demográfico 2010: características gerais da população. Brasília: IBGE, 2010.

IBGE - Instituto Brasileiro de Geografia e Estatística. Síntese de indicadores sociais: uma análise das condições de vida da população brasileira. 2014. Disponível em:

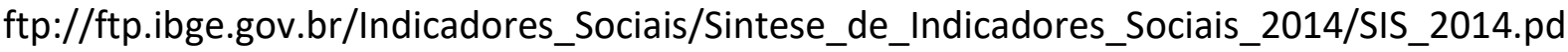
f. Acessado em: 19 ago. 2015.

INCRA. Instrução Normativa no 57, de 2009. Regulamenta o procedimento para identificação, reconhecimento, delimitação, demarcação, desintrusão, titulação e registro das terras ocupadas por remanescentes das comunidades dos quilombos de que tratam o Art. 68 do Ato das Disposições Constitucionais Transitórias da Constituição Federal de 1988 e o Decreto no 4.887, de 20 de novembro de 2003. Brasília, DF: INCRA, 2009.Disponível em: http://www.incra. gov.br/institucional/legislacao--/atos-internos/instrucoes/file/243instrucao-normativa-n-57-20102009. Acesso em: 8 jul. 2015.

JORGE, Amanda Lacerda. O jogo das discursividades: a construção social da categoria "quilombola". Qualificação de Tese (Doutorado em Política Social) - Escola de Serviço Social, Universidade Federal Fluminense, Niterói, 2014.

MEDEIROS, Marcelo; COSTA, Joana. O que entendemos por "feminização" da pobreza? 58. ed. [S. I.]: Centro Internacional da Pobreza: 2008. Disponível em: http://www.ipc-ndp.org /pub/port/IPCOnePager58.pdf. Acesso em: 11 jul. 2015.

MELO, Hildete Pereira de; CASTILHO, Marta. Trabalho reprodutivo no Brasil: quem faz?. Rev. econ. contemp. [online]. 2009, vol.13, n.1, pp.135-158. ISSN 1415-9848. Disponível em: https://doi.org/10.1590/S1415-98482009000100006. Acessado 13 de maio de 2020.

MELO, Hildete Pereira; CASTILHO, Marta. O trabalho reprodutivo no Brasil, quem faz? Revista de Economia Contemporânea, Rio de Janeiro, v. 13, n. 1, 2009.

MELO, Hildete Pereira; OLIVEIRA, André Barbosa. Mercado de trabalho e a previdência social: um olhar feminista. Econômica, Niterói, v. 11, n. 2, dez. 2009.

NOVELLINO, Maria Salet Ferreira. Os estudos sobre feminização da pobreza e políticas públicas para mulheres. In: ENCONTRO NACIONAL DE ESTUDOS POPULACIONAIS, 14., 2004, Caxambú. Anais [...].Caxambú: ABEP, 2004. p. 1-12. Disponível em: http://www.abep.nepo.unicamp.br/site_eventos_abep/PDF/ABEP2004_51.pdf. Acesso em: 8 jul. 2015.

RATTS, Alecsandro J. P. (Re)conhecer quilombos no território brasileiro: estudos e mobilizações. In: FONSECA, Maria Nazareth Soares (org.). Brasil afro-brasileiro. 2. ed. Belo Horizonte: Autêntica, 2006.

ROSA, Waldemir. Sexo e cor: categorias de controle social e reprodução das desigualdades socioeconômicas no brasil. Revista Estudos Feministas, Florianópolis, v. 17, n. 3, p. 889-899, 2009. Disponível em:

https://www.scielo.br/scielo.php?pid=S0104026X2009000300017\&script=sci_abstract\&tIng =pt. Acesso em: 27 jun. 2015. 
SILVA, Eva Aparecida da. Ser remanescente de quilombo em comunidades do Vale do Mucuri: reflexões preliminares de pesquisa. Revista Identidade, São Leopoldo, RS, v. 15, n. 1, jan./jun. 2010.

YAZBEK, Maria Carmelita. Pobreza no Brasil contemporâneo e formas de seu enfrentamento. Serv. Soc. Soc. [online]. 2012, n.110, pp.288-322. ISSN 01016628. Disponível em: https://doi.org/10.1590/S0101-66282012000200005. Acessado em 13 de maio de 2020.

Recebido em: 24/05/2019

Aceito em: 21/02/2020 